\title{
Absorber Tube with Internal Pin-Fins for Solar Parabolic Trough Collector
}

\author{
Kalidasan $\mathrm{B}^{1, \mathrm{a}}$, Shankar $\mathrm{R}^{2}$ and Srinivas $\mathrm{T}^{2}$ \\ ${ }^{1}$ Department of Mechanical Engineering, Bannari Amman Institute of Technology, Satyamangalam-638401, India. \\ ${ }^{2}$ Energy Division, Vellore Institute of Technology, Vellore-632014, India
}

\begin{abstract}
Solar parabolic trough collectors exploit solar energy for power generation in solar thermal power stations. These systems require long arrays of reflective troughs with absorber tube running along the axis of parabolic dish. A successful attempt to reduce the length of arrays was accomplished by experimentally analysing the modifications done in absorber tube. Two out of three tubes were fabricated and they were employed to obtain the performance parameters through experimentation conducted at VIT University, Vellore, India. Distilled water was used as the working fluid. Maximum efficiency of $39.12 \%$ was obtained at 451.6 $\mathrm{W} / \mathrm{m}^{2}$ of direct normal irradiance (DNI) for absorber tube with internal pin-fins and without glass tube $\left(\mathrm{AFWG}_{\mathrm{t}}\right)$ compared to $8.15 \%$ obtained at same value of DNI and other conditions for simple absorber tube without glass cover $\left(\mathrm{AWG}_{\mathrm{t}}\right)$. Cylindrical parabolic trough available at the university was utilized, providing the basis for designing and fabrication of the tubes. Plots for varying mass flow rate at interval of 10 minutes were made against instantaneous thermal efficiency and heat utilized, for direct normal irradiance vs. temperature difference across the tubes and instantaneous thermal efficiency. Through the experimentation conducted, better performance was procured compared to earlier works. Thus, the proposal infers that absorber tube with internal fins has good scope for its application, both domestically as well as industrially. It also calls for further research and development of proposed techniques so as to achieve better performance curves.
\end{abstract}

\section{Introduction}

As by Fernandez-Garcia et al. (2010) [1] the concentrating systems can be classified into three major categories, point focus concentration, line focus concentration and linear concentration. Concentrating paraboloid concentrators are types of point focus concentrations, whereas parabolic trough collectors lies in category of line focus concentrators and Fresnel collectors lies in the category of linear collectors. Solar parabolic trough collector (SPTC) provides an effective way to harness solar energy providing "one-axis concentration" such that fluid flowing through the absorber tube, gains the concentrated energy and accomplish useful work. Parabolic trough collectors, with water as fluid, are basically used for two major applications, industrial steam generation and water heating application. Former application requires heating of water up to a temperature of range $300-400{ }^{\circ} \mathrm{C}$, while the later requires temperature range of around $100-250^{\circ} \mathrm{C}$.

\footnotetext{
${ }^{a}$ Corresponding author : kalidasan@bitsathy.ac.in
} 
Since many years, researchers are working to optimize the operating performance of SPTC so that rapid heat transfer can take place and overall length of the trough collector can be reduced. Supporting the above statement, the review paper on state of parabolic trough collectors by Price et al. (2012) [2] conveys that intensive research and development is required in this field of SPTC to reduce cost and augment their operation. Work done by Tao et al. (2011) [3] introduces design method and working principle for new type of trough collector with efficient performance of SPTC by introducing widely opened concentrating collectors. However, increase in the width of concentrating apparatus may result to unbalanced design and higher probability of back reflection of the incident solar radiations. To avoid such hindrances, requirement of precise tracking and high cost engrossment will be needed, which add some more minuses to the proposed design. Effort on solar selective coatings by Farooq and Raja (2008) [4] and cobalt electrodeposition on absorber tubes by Barrera et al. (1998) [5] enhance the efficiency for performance of solar devices. But radiation thermal losses may increase with increase in coating temperature, thus results in development of high thermal stresses in the collector tube.

Valenzuela et al. (2006) [6] showed the implementation and development of recirculating operation mode for SPTC, increasing the output temperature and performance of the apparatus. But, the system possesses minor drawbacks concerning the use of steam at high pressures, risk for steam leakage and higher stresses on tube. Experimental work with bimetallic tube by Flores and Almanza (2004) [7] is appreciable, posing a new field for further research. However, employment of bimetallic tube requires high investment and also the proposed tube has very large diameter $(31.7 \mathrm{~mm})$, which affect heat transfer rate. Performance analysis of selectively coated solar collector tube with U-tube by Ma et al. (2010) [8] employing reticulation of working fluid presented results employing very less mass flow rate through the tube, while the tube had unexploited and considerable space to fit in another U-tube. Utilising the available space, performance of the tube could have been optimised. An innovative numerical model evaluation of heat transfer characteristics for porous disc receiver by Ravi Kumar and Reddy, 2009 [9] presents an efficient design of absorber tube, but flow across the tube is very high and also the system will require only pure fluid to avoid accumulation of particles on the tube walls than can be caused by highly interrupted flow through the receiver tube with sequential porous discs.

Although there may be an extensive list of researches, developments and innovations for improving effectiveness of absorber tube, the authors of the paper present another innovative research to enhance efficiency nearly by two to three times compared to that of conventional absorber tubes. The fabrication procedure and experimental analysis for the modifications done in the absorber tube are presented. The proposed solar absorber tube can be employed for application in both line and linear focus concentration apparatuses with numerous advantages as well. With VIT University, Vellore $\left(12.92{ }^{\circ} \mathrm{N}, 79.13^{\circ} \mathrm{E}\right)$ as the experimentation site, the experiments were performed on August 23rd, 2014 with Absorber tube with glass cover (AGt), and on August 25th, 2014 with Absorber tube without glass cover $\left(\mathrm{AWG}_{\mathrm{t}}\right)$ and $\mathrm{Absorber}$ tube with internal fins and without glass cover $\left(\mathrm{AFWG}_{\mathrm{t}}\right)$. Because of unavailability of the glass tube, the experiment on August 25th was performed without evacuated glass cover on both the tubes. Nevertheless, the obtained results are very much accurate and can be compared with available studies as well.

\section{Materials and methods}

Among the three tubes used for the experiments, two tubes were designed and fabricated, excluding absorber tube with glass cover $\left(\mathrm{AG}_{\mathrm{t}}\right)$ that was available from the university. The specifications of cylindrical axis trough collector and the absorber tubes are given in Table 1 respectively. All the tubes were made of copper. Although the total length of the two fabricated tubes was kept as $2 \mathrm{~m}$, effective length of tubes receiving reflected radiations from parabolic trough was $1.5 \mathrm{~m}$ and arrangements were made such that the temperature differences for the fluid across the effective length of the tubes were measured accurately. Parabolic trough available at the university, with rim angle of $120^{\circ}$ and focal length $26.26 \mathrm{~cm}$, was used which has reflective surface of aluminium alloy and reflectivity of about 
$80 \%$. Details for fabrication processes of the tubes and pictures taken during the experiments have been included.

Table 1. Specification of Apparatus.

\begin{tabular}{ccc}
\hline Sl. No & Component & Dimension \\
\hline 1 & Length, $L$ & $1.5 \mathrm{~m}$ \\
2 & Width, $W$ & $0.91 \mathrm{~m}$ \\
3 & Concentration ratio, $C$ & 19 \\
4 & Specific heat of fluid, $C_{p}$ & $4182 \mathrm{~J} / \mathrm{kgK}$ \\
5 & Tilt factor for beam radiation, $R$ & 1.00 \\
6 & Inner diameter, $d$ & $0.013 \mathrm{~m}$ \\
7 & Outer diameter, $D$ & $0.015 \mathrm{~m}$ \\
8 & Inner diameter of glass tube & $0.030 \mathrm{~m}$ \\
9 & Thickness of glass tube & $0.005 \mathrm{~m}$ \\
10 & Vacuum pressure in glass tube & $0.8 \mathrm{bar}$ \\
\hline
\end{tabular}

$\mathrm{AG}_{\mathrm{t}}$, was the conventional tube of specified dimension with glass cover. The enclosed volume in the glass tube was evacuated to develop a low pressure vacuum, thus reducing the heat transfer losses. Due to unavailability of more number of glass tubes, the experiment on other two tubes was performed without evacuated glass cover. $\mathrm{AWG}_{\mathrm{t}}$ was similar to $\mathrm{AG}_{\mathrm{t}}$ with the only difference of the glass tube covering the absorber tube, and thus the tube was subjected to minor heat transfer losses. For $\mathrm{AFWG}_{\mathrm{t}}$, drill holes were made in helical pattern all over the tube at pitch distance of $25 \mathrm{~mm}$ and extrusion using a solid copper wire, $1.5 \mathrm{~mm}$ diameter, was provided at each hole with gas welding on the surface. The length of the extruded wires, functioning as internal pin-fins for the tube, was kept constant at $5 \mathrm{~mm}$. The 3D models for simple absorber tube figure 1 and absorber tube with internal fins figure 2 are presented showing internal design. Feature 'a' presents the isometric view of a section of absorber tube while feature ' $b$ ' presents the front view.

a)

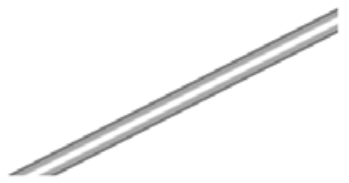

b)

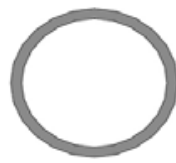

a)

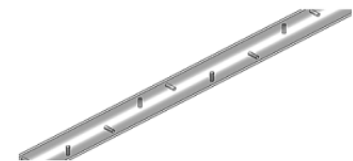

b)

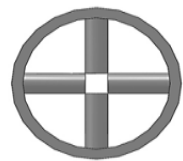

Figure 1. Simple Absorber Tube $\left(\mathrm{AG}_{\mathrm{t}} / \mathrm{AWG}_{\mathrm{t}}\right)$

Figure 2. Absorber Tube with Internal Fins $\left(\mathrm{AFWG}_{\mathrm{t}}\right)$

Initially, absorber tube was fixed on SPTC's axis and the trough was adjusted such that axis of focus and the absorber tube accords. Then the tube was connected to the pump through a hose and distilled water, used as working fluid, was collected in tank. The pump was switched on, leaving the system for 10 minutes with specified volume flow rate, controlled by valves. Parabolic trough collector was adjusted frequently to align the absorber tubes with focus of reflected radiations to maintain tilt factor with the value of $1.00 \pm 2 \%$.Pyrheliometer, with sensitivity of $4.95 \mathrm{mV} / \mathrm{W} / \mathrm{m}^{2}$, was used to measure the beam radiation. The required performance parameters were noted, such as DNI

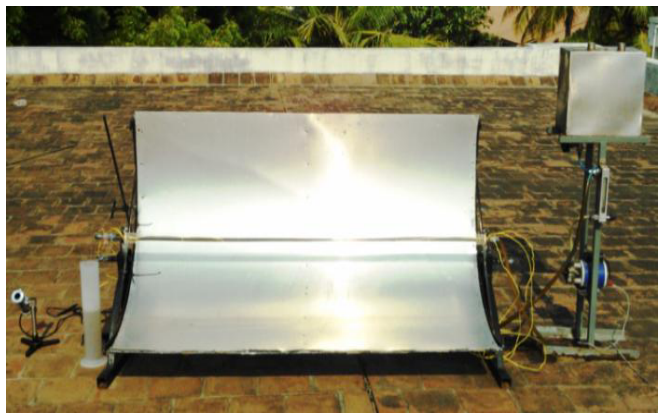

Figure 3. Experimental Set-Up for $\mathrm{AG}_{t}$

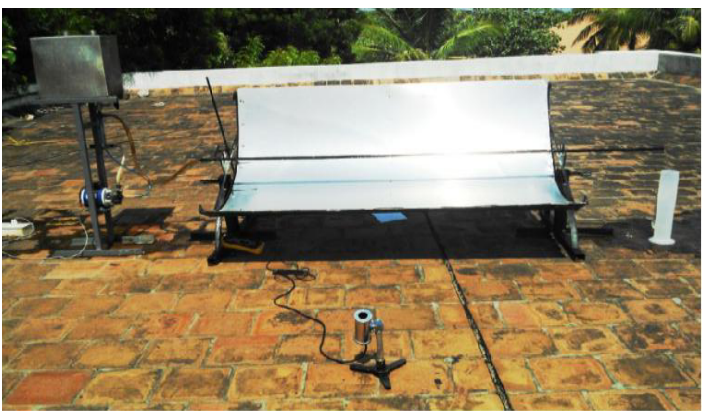

Figure 4. Experimental Set-Up for $\mathrm{AFWG}_{\mathrm{t}}$ 
value from multimeter, temperature values for atmospheric condition, inlet and outlet, and volume flow rates. Then, flow rate was altered at an interval of 10 minutes and data for same parameters was collected at different flow rates. The experiment for each tube was conducted for a span of 50 minutes and total of 5 readings were obtained. The experimental setup for $A_{\mathrm{t}}$ is shown in figure 3 and for $\mathrm{AFWG}_{\mathrm{t}}$ in figure 4 .

A tank of 15 liters capacity was employed to store distilled water that was pumped across the tubes through a valve and a rotameter. Thus, volume flow rates could be varied and experimentation was done with varying mass flow rates. Digital thermocouple was used to measure the temperature values and stop watch for measuring time required to fill a liters capacity collecting jar.

\section{Results and discussions}

Based on the experimental results and observations, plots were obtained for mass flow rate vs. energy utilized in figure 5, mass flow rate vs. instantaneous efficiency in figure 6, DNI vs. temperature difference in figure 7 and DNI vs. instantaneous efficiency in figure 8.

The figure 5 shows that for almost same mass flow rates, the simple tubes, both with and without glass tube, could utilize very less amount of energy ranging from about 50-75 W, while $\mathrm{AFWG}_{\mathrm{t}}$ utilized nearly four-fold of their utilization ranging from 200-250 W. The extrusions or pin-fins provided turbulence in flow with extended surface area for heat transfer and thus higher energy was used. The simple tubes neither provided turbulence nor additional heat transfer resulting to their lowest transfer rates. Hence, in figure 6, the instantaneous efficiencies follow the same increasing trend with $\mathrm{AWG}_{\mathrm{t}}$ having the lowest performance efficiency, almost equal to that obtained by $\mathrm{AG}_{\mathrm{t}}$ and $\mathrm{AFWG}_{\mathrm{t}}$ resulted to highest performance efficiency of range 35-40\%, about three times increment from $\mathrm{AWG}_{\mathrm{t}}$.

It can be inferred that both efficiency and energy utilized increases with decrease in mass flow rate of the working fluid. The procured results can be very well compared to the results presented by[8].The authors maintained very low mass flow rates of $0.001 \mathrm{~kg} / \mathrm{s}, 0.002 \mathrm{~kg} / \mathrm{s}$ and $0.003 \mathrm{~kg} / \mathrm{s}$ and obtained efficiency of about $35-40 \%$ with higher radiation densities of about $950 \mathrm{~W} / \mathrm{m}^{2}$. In the present work, it should be noticed that $\mathrm{AG}_{\mathrm{t}}$ and $\mathrm{AWG}_{\mathrm{t}}$ utilizes the same amount of energy and delivering almost same thermal instantaneous efficiencies. But, as per theory, energy utilized by $\mathrm{AG}_{\mathrm{t}}$ must be higher than that of $\mathrm{AWG}_{\mathrm{t}}$ with availability of glass cover. This shift can be explained using the fact that performance test for $\mathrm{AWG}_{\mathrm{t}}$ was done on August 25th, when higher radiation intensity was available.

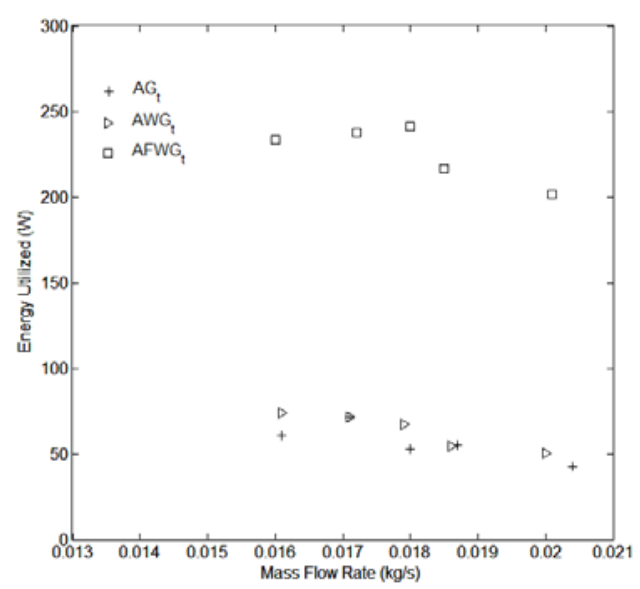

Figure 5. Mass Flow Rate vs. Energy Utilized by Absorber Tubes

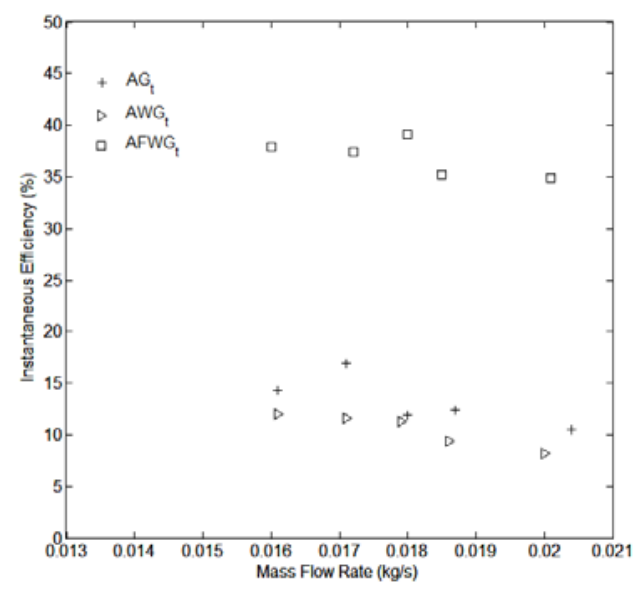

Figure 6. Mass Flow Rate vs. Instantaneous Efficiencies of the Tubes 
Variation of temperature difference across the absorber tubes with varying DNI in figure 7 presents the direct proportionality relation amongst the two parameters i.e. with increase in DNI, temperature difference for the working fluid also increments. Again because of difference in incident radiation intensities, the difference of temperatures for both $\mathrm{AG}_{\mathrm{t}}$ and $\mathrm{AWG}_{\mathrm{t}}$ is almost constant. But, this difference of temperature augments to four times for $\mathrm{AFWG}_{\mathrm{t}}$. The higher temperature verifies the better efficiency of $\mathrm{AFWG}_{\mathrm{t}}$ compared to other absorber tubes, as presented in figure 8. It should be noted that this temperature difference was obtained only for $1.5 \mathrm{~m}$ long SPTC and at low DNI values.

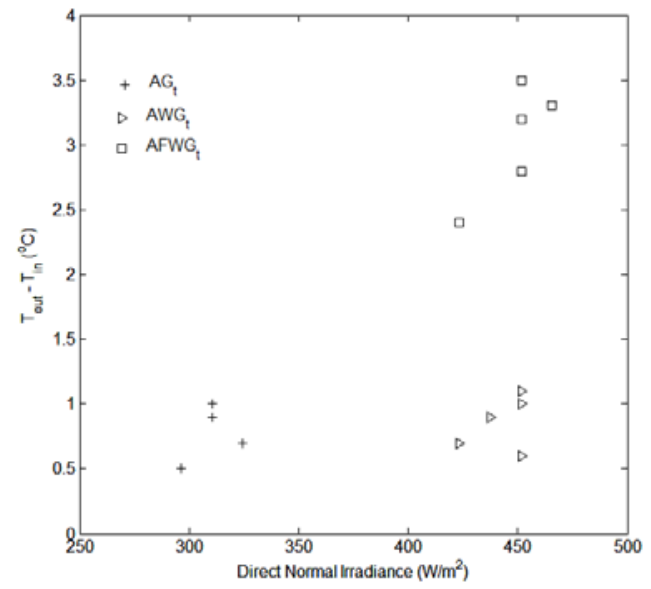

Figure 7. DNI vs. Temp. Difference of Working Fluid Across Absorber Tubes

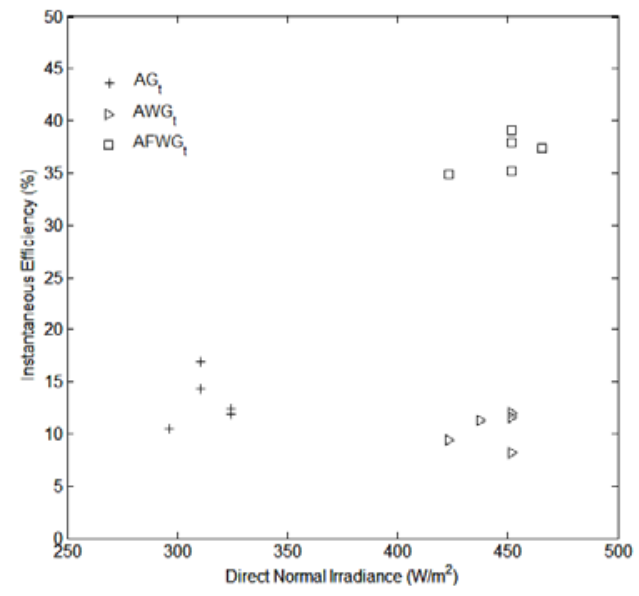

Figure 8. DNI vs. Instantaneous Efficiencies of Absorber Tubes

The experimental data provided by Dudley et al. (1994) [10] for SEGS LS-2 collector, about $4 \mathrm{~m}$ long, used DNI values varying from $900 \mathrm{~W} / \mathrm{m}^{2}$ to $930 \mathrm{~W} / \mathrm{m}^{2}$ with very high inlet temperature of working fluid ranging from $100{ }^{\circ} \mathrm{C}$ to $350{ }^{\circ} \mathrm{C}$ and achieved temperature increment of about $20{ }^{\circ} \mathrm{C}$ in all cases. Whereas, the experimental values provided by the authors for $\mathrm{AFWG}_{\mathrm{t}}$ have DNI values ranging from about $400 \mathrm{~W} / \mathrm{m}^{2}$ to $450 \mathrm{~W} / \mathrm{m}^{2}$ and almost constant inlet temperature of $31.5{ }^{\circ} \mathrm{C}$, achieving temperature rise of $3.5^{\circ} \mathrm{C}$ within the absorber tube length of only $1.5 \mathrm{~m}$. For direct steam generation using parabolic troughs with collector length of $600 \mathrm{~m}$ and inlet temperature of $190{ }^{\circ} \mathrm{C}$, Odeh et al. (1998) [11] presented analysed and developed model achieving maximum efficiency of about $70 \%$, whereas efficiency close to $40 \%$ was achieved for $\mathrm{AFWG}_{t}$, without evacuated glass cover.

The proposed design appears to have substantial application in the developing fields as well. It can be used for thermal applications, involving heat transfer, organic rankine cycles and even in absorption power and cooling cycles, making performance of system efficient.

\section{Conclusion}

Vellore is $216 \mathrm{~m}$ above sea level and receives two periods of monsoons mostly during June - August and October - December. As the experiments were conducted during the second phase of monsoon, intensified solar flux was not available compared to that obtained in summer season, affecting the performance curves of the proposed absorber tubes. Also the arrangement of aluminium alloy sheet over the parabolic trough had minor irregularities, resulting to lessened reflective and optical efficiency compared to mirror reflectors. The unavailability of glass tube for $\mathrm{AFWG}_{\mathrm{t}}$ also contributed to the procured less efficient results. Reduction of overall length of arrays required for harnessing of solar energy, especially for application of direct steam generation in solar thermal power plants, was the prime aim of this project. With the obtained results, it can be concluded that the modifications of internal fins in the absorber tubes of solar parabolic concentrating collector can deliver highly efficient 
performance compared to that of traditional tubes. Average instantaneous thermal efficiencies of $36.89 \%$ were obtained for internally finned tube. Such modifications can be revolutionary in the field of solar energy, hence cutting off the overall cost of the projects to a great extent. It can be inferred that absorber tube with internal pin-fins proves to be most efficient, although there was a con for the experimentation that use of evacuated glass cover was avoided due to lack of sufficient funding. If evacuated glass cover are used, better and more efficient results could have been obtained compared to the various referred works.

\section{References}

1. A. Fernandez-Garcia, E. Zarza, L. Valenzuela, M. Perez, Renew. and Sustain. Energy Rev. 14, 1695-1721 (2010)

2. H. Price, E. Lupfert, D. Kearney, E. Zarza, G. Cohen, R. Gee, R. Mahoney, J. of Sol. Energy Eng. 124, 109-125 (2012)

3. T. Tao, Z. Hongfei, H. Kaiyan, A. Mayere,. Sol. Energy 85, 198-207 (2012)

4. M. Farooq, I.A. Raja, Renew. Energy 33, 1275-1285 (2008)

5. E. Barrera, I. Gonzalez, T. Viveros, Sol. Energy Mater. and Sol. Cells 51, 69-82 (1998)

6. L. Valenzuela, E. Zarza, M. Berenguel, E.F. Camacho, Sol. Energy 80, 1-17. (2006)

7. V. Flores, R. Almanza, Energy 29, 645-651. (2004)

8. L. Ma, Z. Lu, J. Zhang, R. Liang, Build. and Environ. 45, 1959-1967. (2010)

9. K. Ravi Kumar, K.S. Reddy, Appl. Energy 86, 1804-1812. (2009)

10. V.E. Dudley, G.J. Koib, M. Sloan, D. Kearney, D., Test results SEGS LS-2 solar collector, Sandia National Laboratories, 1994

11. S.D. Odeh, G.L. Morrison, M. Behnia,. Sol Energy 62, No. 6, 395-406. (1998) 